\title{
NUEVOS YACIMIENTOS CAMPANIFORMES EN LA PROVINCIA DE SEVILLA
}

Diego Ruiz Mata

En esta nota breve queremos informar de tres yacimientos con cerámicas decoradas al estilo campaniforme, que hemos creído de interés para el conocimiento de este horizonte cultural en la cuenca del río Guadalquivir. El material, que se publica, es el resultado de diversas prospecciones en los yacimientos de Las Arenas, en el término municipal de La Algaba (figura 1, núm. 6), Cerro Casar, término municipal de El Coronil (1) (figura 1, núm. 8) y revisión, por último, de algunos materiales de El Carambolo (figura 1, núm. 4).

\section{LAS ARENAS}

El yacimiento está situado a unos 2 kilómetros al norte de La Algaba, en la carretera hacia Alcalá del Río, detrás de la Venta del Cúchara, y sobre elevación de poca altura que recibe el nombre de Las Arenas. En la actualidad ha desaparecido casi por completo a causa de su desmantelamiento para la extracción de gravas destinadas a la construcción. Al finalizar estos trabajos fuimos avisados de la aparición de cerámicas y restos de construcciones antiguas (2). Realizamos diversas prospecciones con objeto de salvar los pocos restos existentes de este interesante yacimiento en pleno valle del Guadalquivir. Por los materiales se deduce que fue habitado por vez primera en plena Edad de Cobre, con cerámicas afines con las del yacimiento cercano de Valencina de la Concepción, perdurando hasta el Bronce final (3). Después de un hiatus, los restos más modernos son ya romanos, residuos de una villa de época imperial.

(1) Material recogido por don Antonio Lara ( $\dagger$ ).

(2) Queremos agradecer desde estas líneas la comunicación del Comandante de Puesto de la Guardia Civil de La Algaba, gracias a la cual conocimos el yacimiento y se pudieron recoger los fragmentos que publicamos.

(3) Material que estudiamos y publicamos en una monografía sobre el Bronce final. Se recogieron cazuelas carenadas y decoraciones bruñidas. 
No obstante, los fragmentos más numerosos corresponden a cerámicas con decoración campaniforme (4), que seguidamente analizamos.

INVENTARIO DEL MATERIAL

Figura 2

1. Cazuela de sección hemisférica y borde aplanado. Pasta castaña. Superficies bruñidas, castañas. Decoración mediante diseños geométricos, realizados con ruedecilla o peine de base cuadrada. Parte superior del borde decorado mediante rombos impresos.

2. Cazuela, de borde más amplio y aplanado, que origina una arista aguda hacia el interior. Superficies bruñidas, grisáceas. Superficie exterior decorada mediante incisiones profundas. Borde decorado con líneas entrecruzadas incisas. En los surcos hay vestigios de pasta blanca.

3. Cazuela, de borde almendrado y aristado al interior. Superficie interior espatulada, negruzca. Superficie exterior alisada, castaña. Superficie exterior decorada con líneas incisas realizadas con punzón. Borde decorado con líneas entrecruzadas incisas.

4. Cazuela, de borde aplanado y aristado al interior. Superficie interior espatulada, gris oscura. Superficie exterior alisada, con pulimento, decorada con líneas horizontales paralelas realizadas con peine o ruedecilla. Borde decorado con líneas quebradas impresas con peine o ruedecilla.

5. Cazuela, de borde aplanado y aristado al interior. Superficie interior bruñida, gris oscura. Superficie exterior bruñida, castaña. Superficie exterior decorada mediante líneas paralelas incisas. Borde con decoración lineal incisa.

6. Cuenco. Superficies alisadas, grisáceas. Superficie exterior decorada mediante decoración lineal incisa.

7. Borde perteneciente a un vaso abierto. Superficie interior alisada, negruzca. Superficie exterior recubierta de engobe castaño. Decoración exterior lineal realizada mediante impresiones de peine o ruedecilla.

8. Cuenco. Superficies bruñidas, recubiertas de engobe rojizo o almagra. No posee decoración.

9. Fragmento perteneciente a un vaso posiblemente acampanado. Pasta rojiza. Superficies alisadas. Superficie exterior decorada mediante líneas incisas.

10. Galbo de vaso abierto acampanado. Pasta muy fina y depurada, grisácea. Superficies alisadas. Superficie exterior decorada mediante se-

(4) Nos informaron en el yacimiento y en la Venta del Cuchara que aparecieron numerosos vasos completos que vendieron. 
ries de líneas horizontales impresas con ruedecilla o peine y líneas quebradas incisas con punzón.

11. Galbo de vaso acampanado. Pasta negruzca. Superficies bruñidas, acastañadas. Superficie exterior decorada mediante impresiones de peine o ruedecilla.

12. Galbo de vaso abierto. Pasta rojiza. Superficies alisadas. Superficie exterior decorada mediante impresiones de peine o ruedecilla.

\section{Figura 3}

1. Fragmento de galbo. Pasta anaranjada. Superficie interior espatulada y la exterior bruñida. Pared exterior decorada con líneas quebradas realizadas mediante impresiones de peine o ruedecilla.

2. Fragmento de galbo. Superficie interior alisada y la exterior bruñida. Decoración exterior mediante impresiones de peine o ruedecilla.

3. Fragmento de galbo. Superficies alisadas, grisácea la interior y la exterior anaranjada. Superficie exterior decorada mediante impresiones de peine o ruedecilla.

4. Fragmento de galbo. Pasta rojiza. Superficies alisadas. Pared exterior decorada con líneas horizontales y verticales incisas.

5. Fragmento de galbo. Pasta negruzca. Superficies alisadas, negruzcas. Superficie exterior decorada mediante líneas horizontales realizadas con peine o ruedecilla, que apenas destaca, y línea quebrada incisa.

6. Fragmento de galbo. Pasta negruzca. Superficies alisadas, negruzcas. Superficie exterior decorada con líneas horizontales y quebradas incisas.

7. Fragmento de galbo. Pasta grisácea. Superficies bruñidas, negruzcas. Superficie exterior decorada mediante líneas incisas.

8. Fragmento de galbo. Pasta negruzca. Superficie interior alisada, negruzca, y exterior bruñida, castaña. Pared exterior decorada mediante impresiones de peine o ruedecilla.

9. Fragmento de galbo. Pasta negruzca. Superficies alisadas con pulimento, castañas. Superficie exterior decorada mediante incisiones.

10. Fragmento de galbo. Pasta negruzca. Superficies alisadas, grisáceas. Decoración exterior mediante incisiones, realizadas con un punzón afilado que ha penetrado mucho en el barro humedecido.

11. Fragmento de galbo. Pasta negruzca. Superficies alisadas, negruzcas. Superficie exterior decorada mediante líneas incisas realizadas con punzón.

12. Fragmento de galbo. Pasta rojiza. Superficies rojizas, alisada la 
interior y muy bien bruñida la exterior. Decoración exterior mediante impresiones de peine o ruedecilla.

13. Galbo de un vaso de gran tamaño. Superficie interior mal espatulada, negruzca. Superficie exterior muy tosca, castaña. Superficie exterior decorada mediante impresiones de rueda o peine.

Figura 4

1. Cazuela, de borde aplanado. Pasta negruzca. Superficies bruñidas, castaña oscura la interior y más clara la exterior. Decoración lineal en superficie exterior y borde realizada con punzón.

2. Fragmento de vaso, posiblemente acampanado. Pasta negruzca. Superficies recubiertas de engobe espeso anaranjado. Decoración exterior lineal realizada con punzón.

3. Cuenco. Pasta negruzca. Superficies bruñidas, negruzcas.

\section{Figura 5}

1. Borde de un vaso acampanado. Pasta gris oscura. Superficies alisadas, con pulimento, grisáceas. Decoración exterior mediante líneas incisas.

2. Fragmento de galbo. Pasta castaña rojiza. Superficies alisadas, con brillo, castañas rojizas. Decoración exterior realizada mediante peine o ruedecilla.

3. Fragmento de galbo. Pasta anaranjada. Superficies bruñidas, del color de la pasta. Decoración exterior lineal realizada mediante impresiones de peine o ruedecilla.

4. Fragmento de galbo y arranque de cuello. Pasta negruzca. Superficies alisadas con tosquedad, sin pulimento, castañas oscuras. Decoración exterior mediante impresiones de peine o ruedecilla.

5. Fragmento de galbo. Pasta castaña oscura. Superficies alisadas, con pulimento, grises oscuras. Decoración lineal exterior incisa.

\section{Figura 6}

1. Fragmento de galbo y arranque de cuello. Pasta castaña oscura. Superficies alisadas, negruzcas. Superficie exterior decorada mediante impresiones realizadas con peine o ruedecilla.

2. Fragmento de galbo. Pasta negruzca. Superficies alisadas, negruzcas. Decoración exterior mediante peine o ruedecilla.

3. Fragmento de galbo. Pasta castaña. Superficies alisadas, castañas oscuras. Superficie exterior decorada mediante rueda o peine. 
4. Fragmento de galbo. Pasta castaña rojiza. Superficies alisadas, con brillo, anaranjadas. Decoración exterior mediante peine o ruedecilla.

5. Fragmneto de galbo. Pasta castaña. Superficies alisadas, sin brillo, negruzcas. Decoración exterior mediante impresiones de peine o ruedecilla.

6. Cuenco. Pasta castaña rojiza. Superficies alisadas, con brillo, castañas. Decoración exterior incisa, realizada con punzón.

\section{Figura 7}

1. Galbo posiblemente de un vaso de cuello acampanado. Pasta negruzca. Superficies ligeramente alisadas, sin brillo, negruzcas. Decoración exterior mediante impresiones de ruedecilla o peine.

2. Cazuela de borde aplanado. Pasta anaranjada. Superficies espatuladas, con brillo, anaranjadas. Pared exterior y borde decorados mediante impresiones de peine o ruedecilla.

3. Borde de un vaso acampanado. Pasta negruzca. Superficies bruñidas, negruzcas. Decoración exterior lineal incisa.

4. Cuenco. Pasta castaña oscura. Superficies alisadas, sin brillo, negruzcas. Pared exterior y borde decorados mediante impresiones de peine o ruedecilla.

5. Borde de un vaso de cuello acampanado. Pasta negruzca. Superficies alisadas, sin brillo, castañas oscuras. Decoración exterior mediante peine o ruedecilla.

6. Borde de un vaso de cuello acampanado. Pasta castaña rojiza. Superficies alisadas, castañas. Decoración exterior mediante impresiones de peine o ruedecilla.

7. Plato de borde achaflanado. Pasta castaña porosa. Superficies mal alisadas, castañas. Decoración exterior y borde mediante impresiones de peine o ruedecilla.

\section{EL CARAMBOLO}

La colina de El Carambolo está situada en la fachada oriental de la meseta del Aljarafe sevillano, a unos 3 kilómetros al oeste de Sevilla, y posee una cota de 91 metros sobre el nivel del mar. Con motivo del hallazgo de unas piezas de oro en su cima en 1958, se practicaron excavaciones posteriormente en los poblados del Bronce final y orientalizante (5). Proceden de allí varios fragmentos campaniformes, publicado uno de ellos por Carriazo Arroquia (6) como cerámica de "punto en raya", junto

(5) J. DE M. Carriazo, Tartesos y El Carambolo, Madrid 1973.

(6) J. DE M. Carriazo, Tartesos y El Carambolo, 1973, figura 418. 
a otros incisos del Bronce final, que calificó como cerámicas de tradición neolítica. Recientemente hemos tenido la oportunidad de dibujar parte del material del yacimiento (7) y comprobar la existencia de tres fragmentos campaniformes y otros sin decoración de la Edad del Cobre. Desconocemos con exactitud la circunstancia de su hallazgo, pero hemos comprobado que en las laderas de la colina se han recogido alguna vez fragmentos calcolíticos. Suponemos que están directamente relacionados con el poblado cercano de Valencina de la Concepción.

INVENTARIO DEL MATERIAL

Figura 8

1. Procede del poblado bajo. Galbo y arranque de un cuello, probablemente acampanado. Pasta negruzca. Superficie interior mal alisada, negruzca. Superficie exterior mal alisada, aflorando los desgrasantes, castaña rojiza. Decoración exterior mediante peine o ruedecilla.

2. Galbo de un vaso abierto. Pasta negruzca. Superficies alisadas, castañas oscuras. Decoración exterior mediante peine o ruedecilla. Procede del poblado bajo.

3. Procede del poblado bajo. Galbo de un vaso abierto, probablemente acampanado. Pasta negruzca. Superficies de mala calidad, alisadas sin esmero, negruzcas. Decoración exterior mediante peine o ruedecilla.

\section{CERRO CASAR}

El Cerro Casar es uno de los montículos de las Lomas del Alcázar, que posee una cuota de 171 metros sobre el nivel del mar, y está situado a la mitad de camino y al pie de la carretera Utrera-El Coronil. El yacimiento posee una estratigrafía amplia que abarca culturalmente desde la Edad de Cobre hasta época romana. Los poblados prehistóricos ocuparon la cima y las laderas y la población romana se extendió por la llanura. Los fragmentos proceden de prospecciones realizadas por don Antonio Lara (8), que amablemente permitió sus dibujos (9).

(7) Desde aquí queremos agradecer todas las facilidades concedidas por la doctora Fernández-Chicarro $(\dagger)$, directora del Museo Arqueológico de Sevilla, y don Fernando Fernández Gómez, conservador del mismo.

(8) La colección de don Antonio Lara se nutrió en gran parte de este yacimiento. La mayor parte del material de esta colección la adquirió el Museo Arqueológico de Sevilla.

(9) Los dibujos los realizó don Francisco Gómez Toscano, a quien agradecemos su amabilidad de ofrecérnoslo para este trabajo. 
INVENTARIO DEL MATERIAL

a. Plato de borde almendrado. Pasta gris oscura. Superficies alisadas, con brillo, grisáceas. Decoración incisa por el exterior y zona superior del borde.

b. Plato o fuente de borde engrosado y apuntado al interior. Pasta grisácea. Superficies alisadas, grisáceas. Decoración exterior y zona superior del borde realizada con peine o ruedecilla.

c. Cuenco. Pasta castaña negruzca. Superficies alisadas, castañas. Decoración exterior realizada con peine o ruedecilla.

d. Cuello de vaso acampanado. Pasta castaña. Superficies alisadas, con brillo, castañas. Decoración exterior mediante ruedecilla o peine. Estilo Internacional.

e. Cuenco. Pasta negruzca. Superficies alisadas, negruzcas. Decoración exterior mediante ruedecilla o peine.

f. Fragmento de galbo. Pasta gris oscura. Superficies alisadas, grisáceas. Decoración exterior con peine o ruedecilla.

g. Galbo de un vaso abierto. Pasta grisácea. Superficie exterior alisada, con brillo, grisácea. Decoración exterior lineal mediante incisiones.

h. Galbo. Pasta castaña. Superficie exterior alisada. Decoración exterior mediante peine o ruedecilla.

i. Borde, quizás de cazuela, decorado con incisiones.

j. Galbo. Pasta castaña. Superficie exterior alisada, castaña, deco. rada mediante impresiones de peine o ruedecilla.

k. Galbo de un vaso abierto. Pasta grisácea. Superficie exterior alisada, con brillo, gris oscura. Decoración exterior mediante peine o ruedecilla.

1. Borde de un vaso abierto. Superficie exterior alisada, grisácea, decorada con peine o ruedecilla.

m. Galbo. Supercies alisadas, grisáceas. Decoración interior y exterior mediante peine o ruedecilla.

\section{CONCLUSIONES GENERALES}

Advirtamos, en primer lugar, que todos los fragmentos descritos se recogieron casualmente en prospecciones y, por tanto, al margen de un contexto estratigráfico que precisase su cronología.

En Las Arenas, los tipos pertenecen a las cazuelas de bordes aplanados (figuras $2: 1 ; 4: 1 ; 7: 2$ ) y engrosados y aristados al interior (figura 2: $2,3,4)$, que se pueden asociar con el complejo de Carmona y, a su vez, con los tipos de Palmela (10). Los cuencos también están presentes (figu-

(10) R. J. Harrison, T. Bubner y V. A. Hibss: The Beaker Pottery from El Acebuchal, Carmona (prov. Sevilla), Madr. Mitt. 17, 1976, fig. 40, fragmentos 222 a 226. 
ras $2: 6 ; 6: 6 ; 7: 4$ ) y los platitos de borde aguzado (figura $7: 7$ ). En las formas cerradas se han recogido fragmentos de vasos acampanados de perfiles en $S$ suaves (figuras $2: 9$ y $10 ; 4: 2$ ). Otros fragmentos señalan un cuello alto y abiertos (figuras 5: 1; 7:3), frecuentes en El Acebuchal (11). El fragmento 11 de la figura 2 pertenece al Estilo Marítımo o Internacional. Las decoraciones no se apartan de las conocidas del complejo Guadalquivir-Carmona (12), en la doble modalidad del uso de ruedecillas o incisión.

Los fragmentos del Cerro Casar son también afines a los de Carmona. Destaquemos sólo el fragmento $\mathrm{m}$ de la figura 9, decorado por el interior y exterior.

El complejo de Carmona se ha fechado recientemente entre 1500/14001200 a. de C. (13), en base, sobre todo, a la aparición en El Acebuchal de un soporte, decorado al estilo campaniforme, cazuela con decoración reticulada bruñida interior y cuencos con pies cónicos, que se han relacionado con los argáricos. No poseemos elementos suficientes para debatir o corroborar la cronología propuesta, pero señalamos que los soportes se registran en el poblado de Valencina de la Concepción en un contexto de la Edad de Cobre (14) y también en sepulturas eneolíticas de Hidalgo, entre Sanlúcar de Barrameda y Chipiona (15), y las decoraciones bruñidas son muy frecuentes en este mismo horizonte en Valencina de la Concepción (16) y anteriores a las del Bronce final conocidas. Además, el ambiente en que fueron recogidos los fragmentos de Las Arenas está asociado al poblado de Valencina de la Concepción que posee una cronología anterior a la propuesta.

(11) Art. cit. en nota anterior, figs. 1-21.

(12) Art. cit. en nota $10 \mathrm{y} \mathrm{R}$. J. HARRISON, The Bell Beaker of Spain and Portugal, American School of Prehistoric Research, Bulletin 35, 1977, págs. 26 y 69-72. Contiene abundante bibliografía.

(13) Harrison, Bubner y HibBs, Madr. Mitt. 17, 1976, págs. 85-87.

(14) Excavaciones de D. Ruiz Mata y F. Fernández.

(15) J. DE CARRIAZo: El dólmen de Hidalgo (junto a la desembocadura del Guadalquivir) y las contiguas sepulturas de fosa eneolíticas, XIII CAN, Huelva 1973, Zaragoza 1975 , págs. 327 y ss.

(16) D. Ruiz Mata, en Madr. Mit. 15, 1976, págs. 80 y ss.; F. Fernández y D. Ruiz Mata: El tholos del Cerro de la Cabeza, en Valencina de la Concepción (Sevilla), Trabajos de Prehistoria, 35, 1978, págs. 193 y ss. 


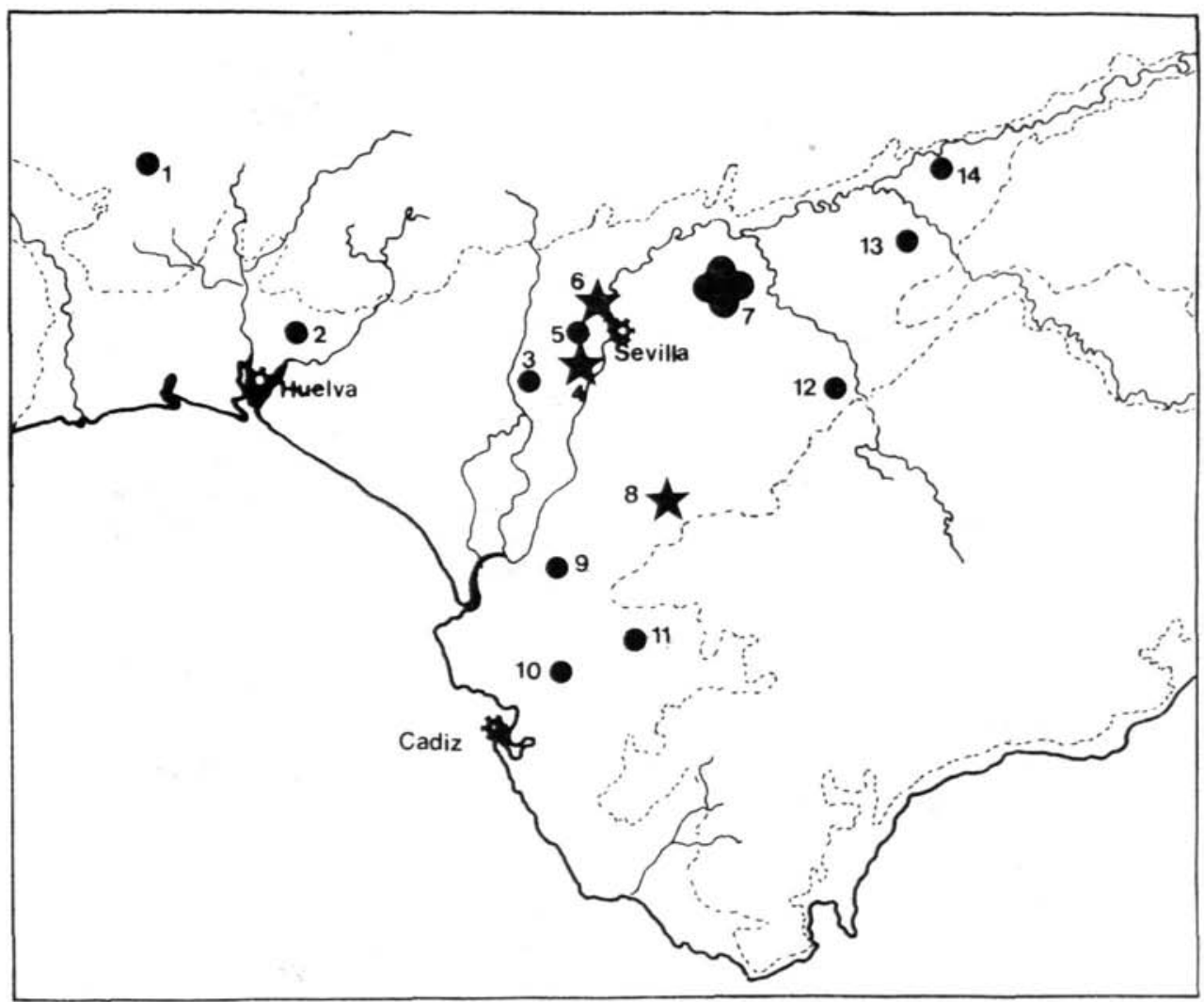

Fig. 1. - Distribución de la cerámica campaniforme en la cuenca del Guadalquivir. Las estrellas señalan los emplazamientos de los yacimientos que analizamos. 1. La Zarcita; 2. Trigueros; 3. Aznalcazar; 4. El Carambolo; 5. Valencina de la Concepción; 6. Las Arenas; 7. Núcleo de Los Alcores de Carmona; 8. Cerro Casar; 9. Lebrija; 10. Asta Regia; 11. Arcos de la Frontera; 12. Marchena; 13. Cañada del Rosal; 14. Fuente Palmera 

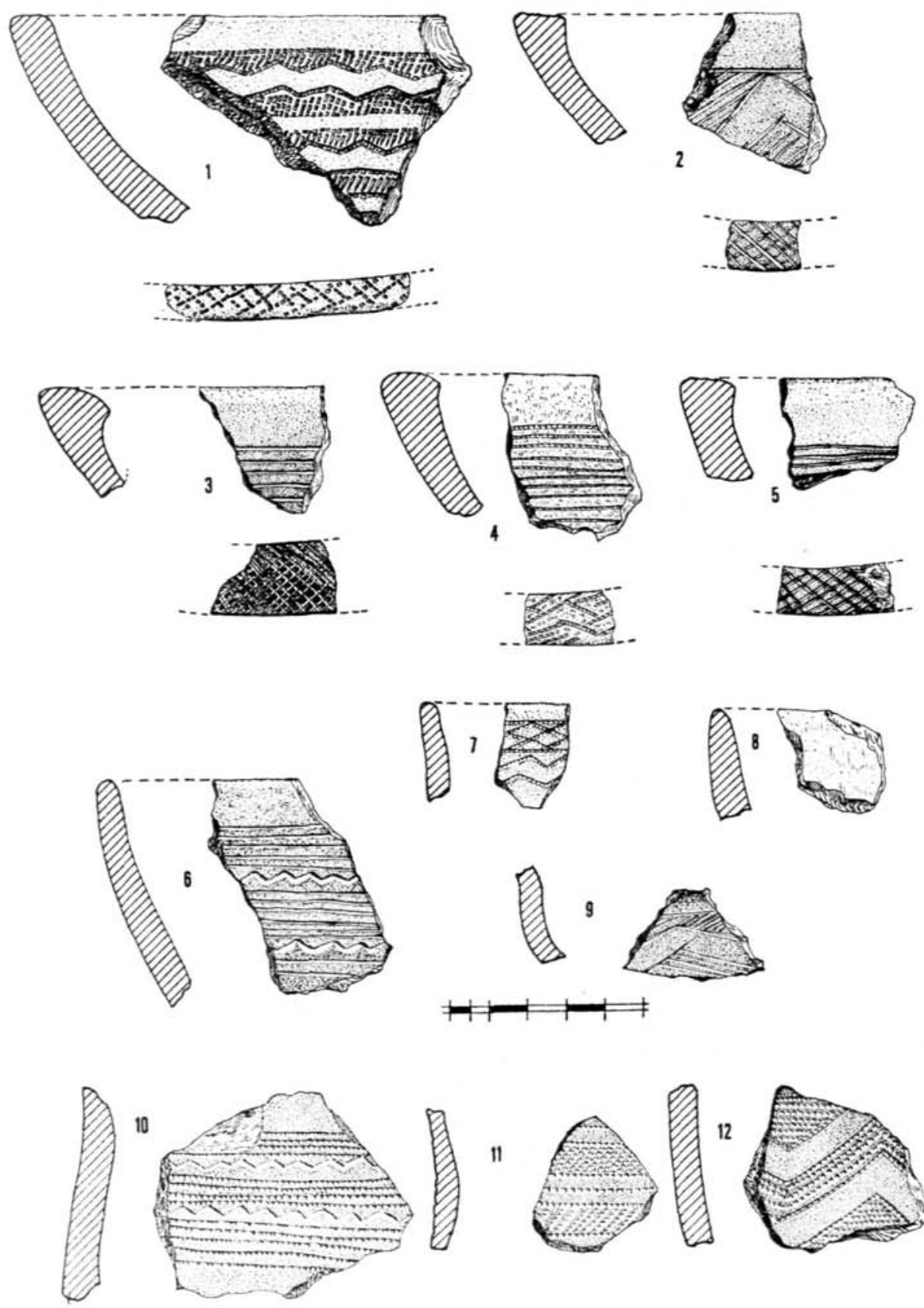

FIG. 2. - Las Arenas (La Algaba) 

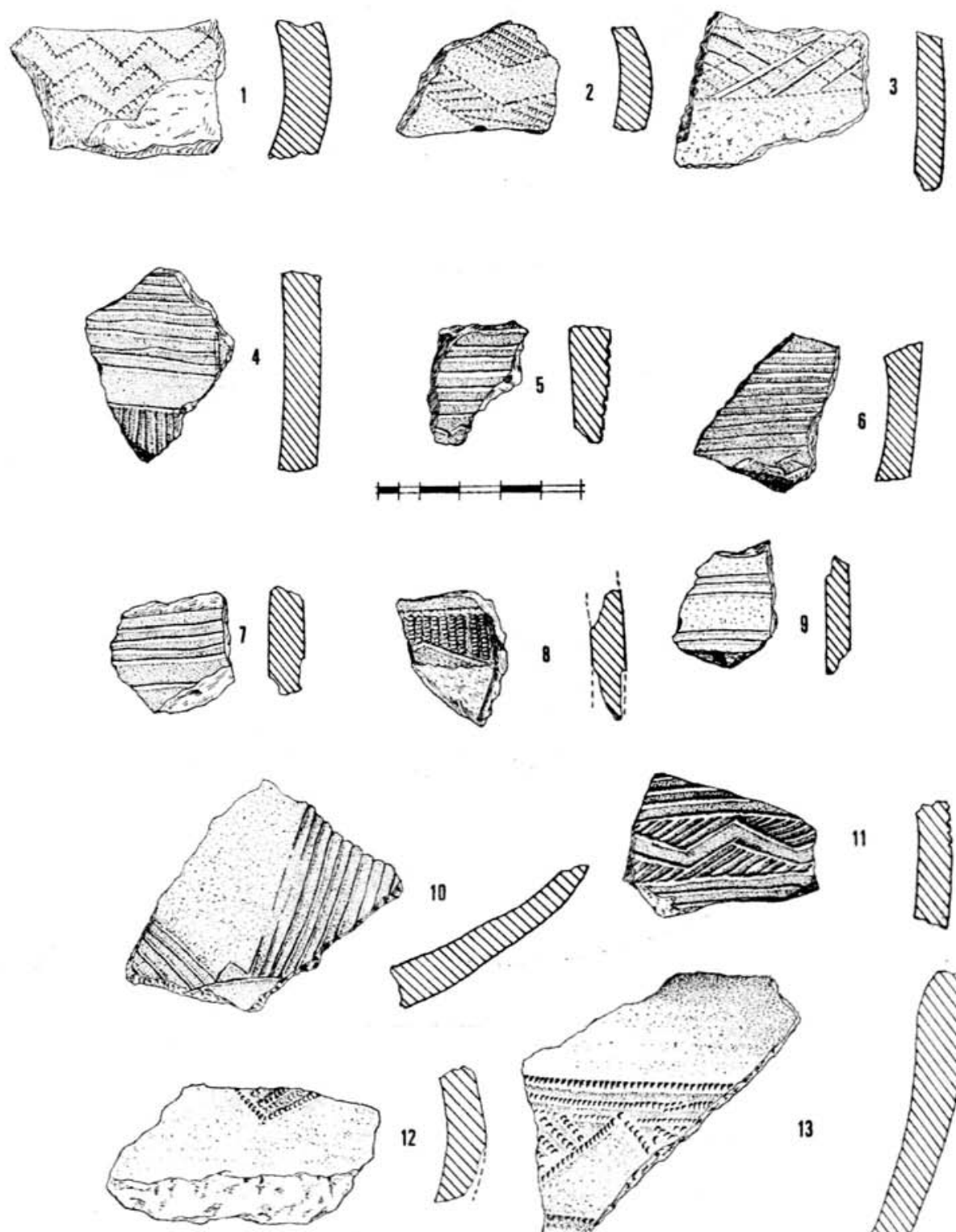

12
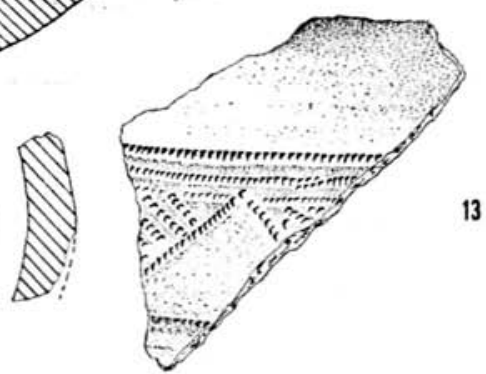

13

FIg. 3-Las Arenas (La Algaba) 

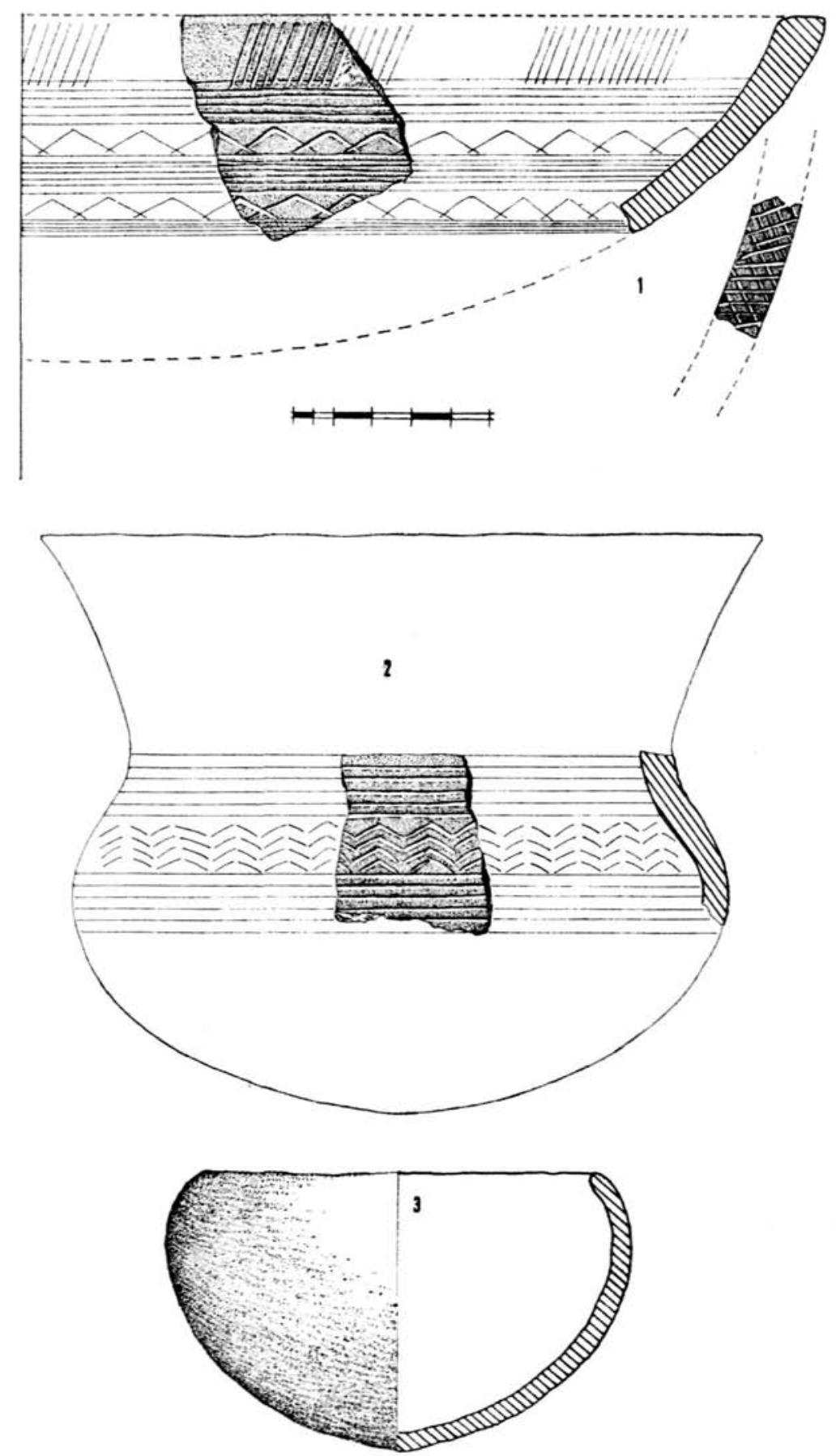

Fig. 4. - Las Arenas (La Algaba) 

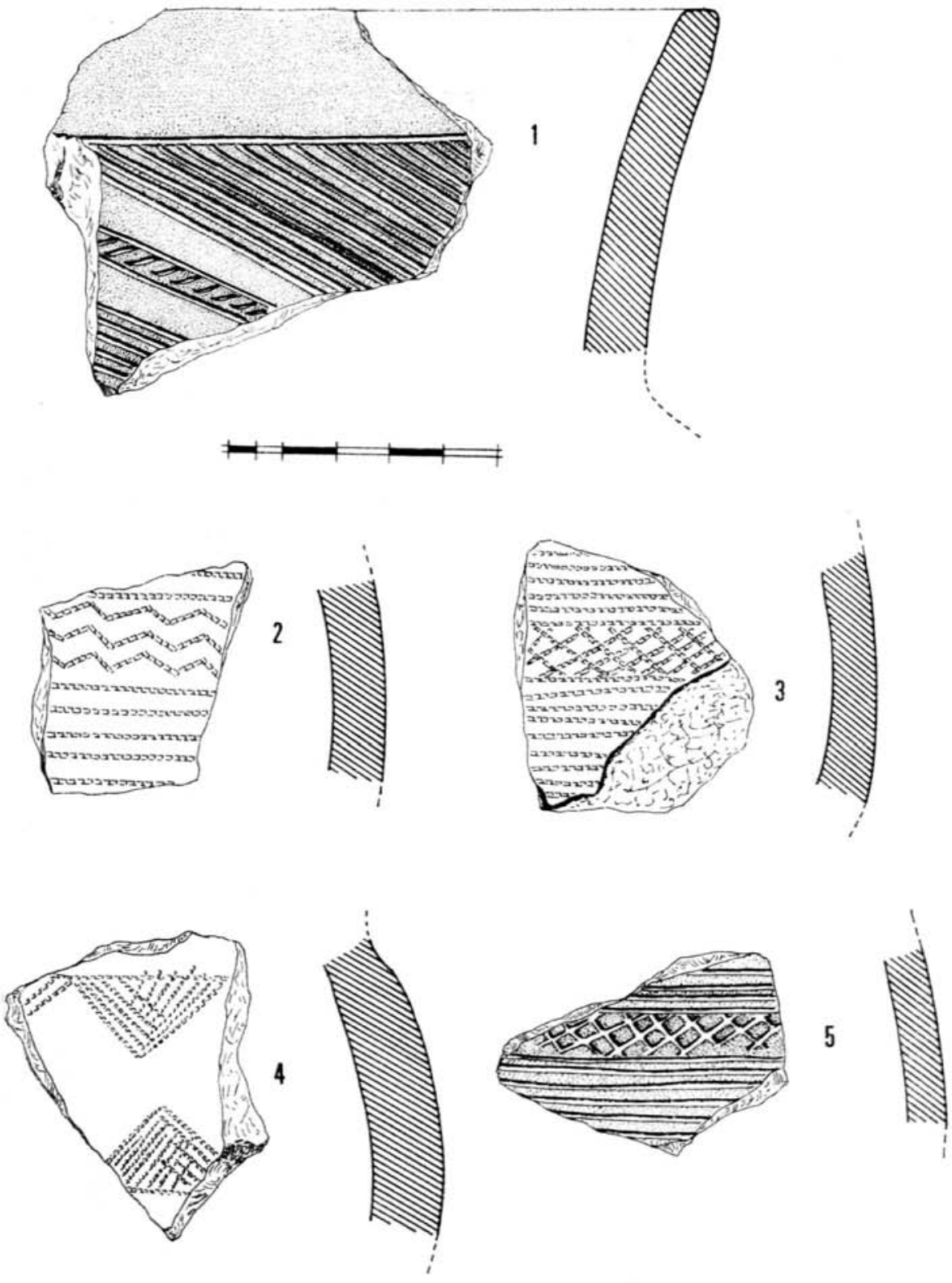

Fig. 5. - Las Arenas (La Algaba) 

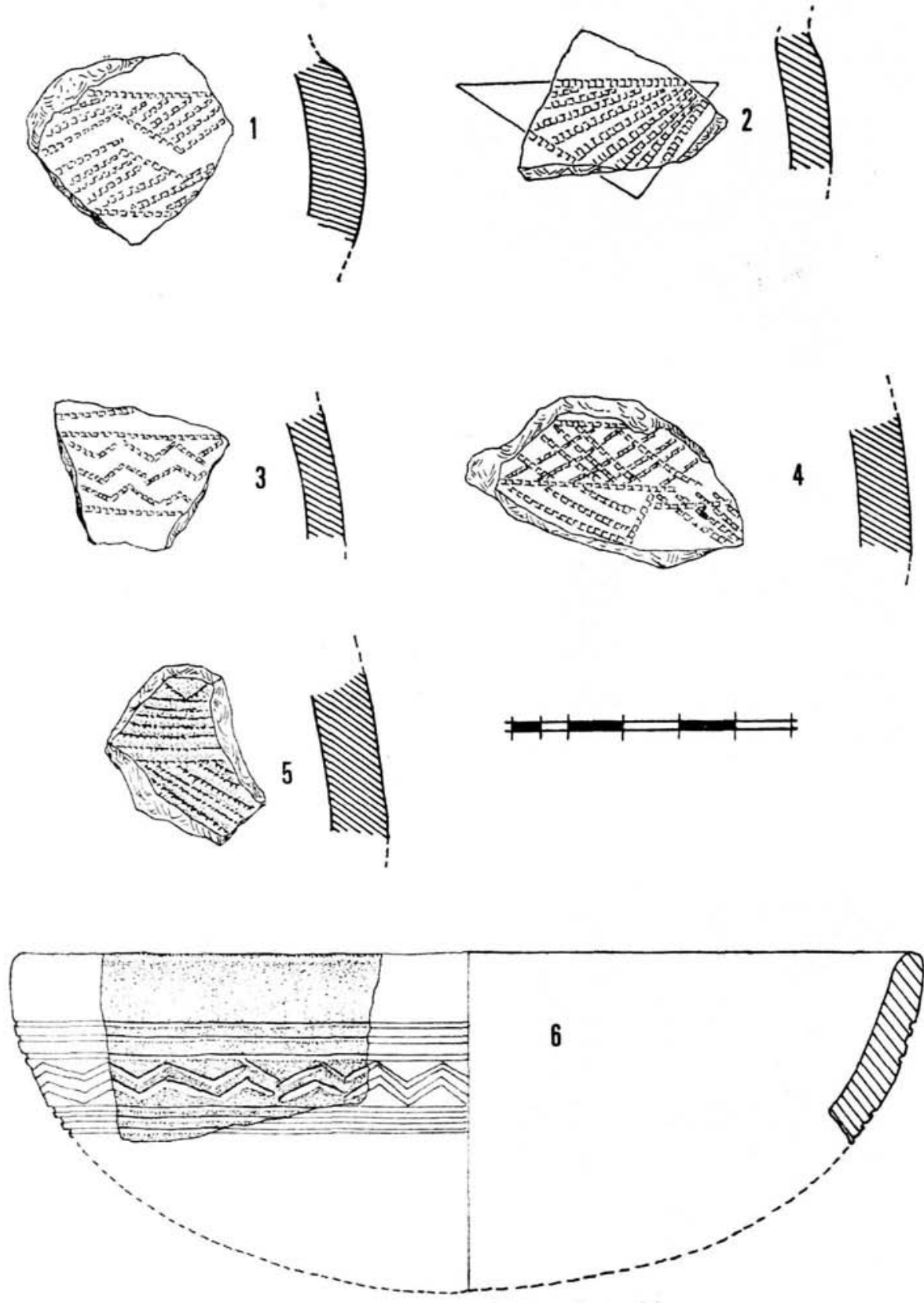

Fig. 6. - Las Arenas (La Algaba) 

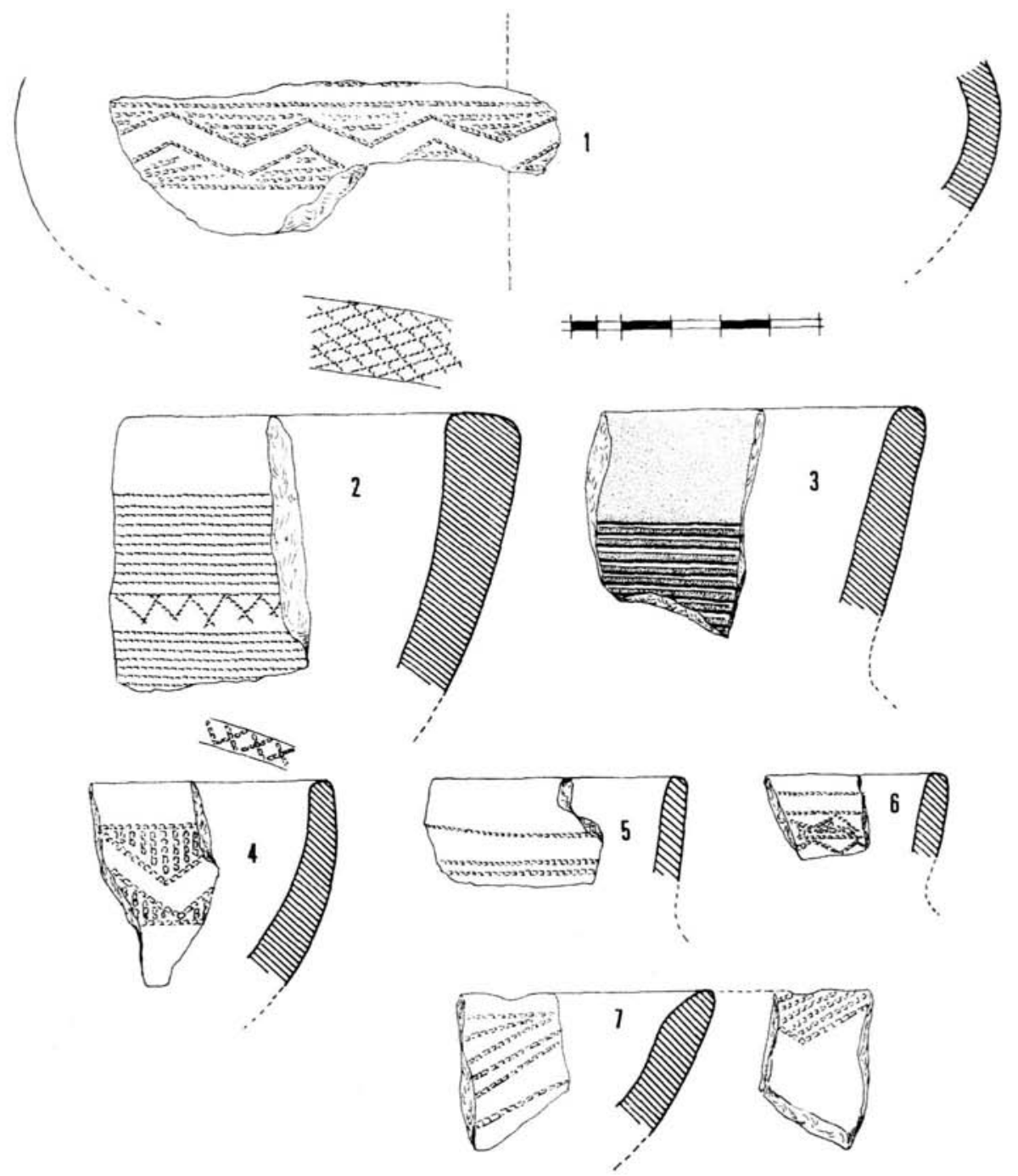

Fig. 7. - Las Arenas (La Algaba) 

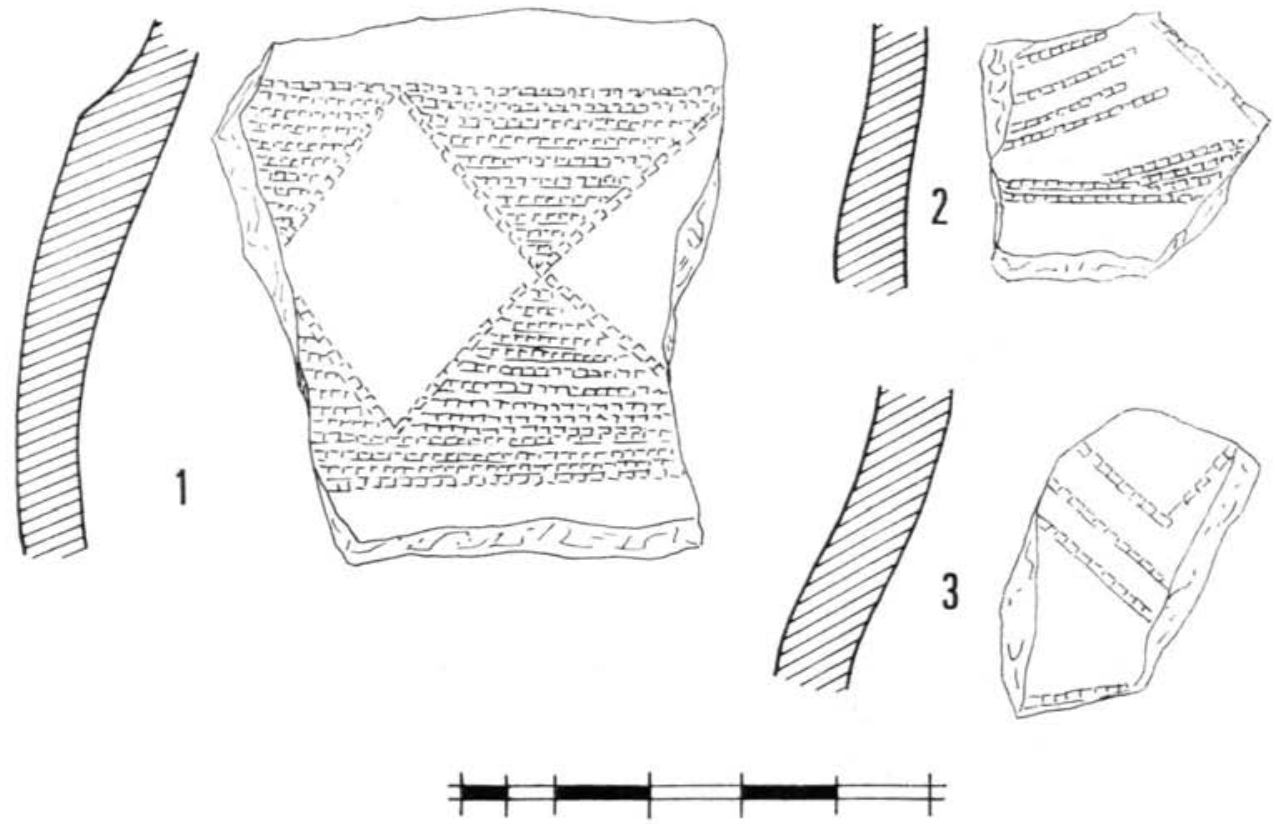

FIG. 8-El Carambolo 


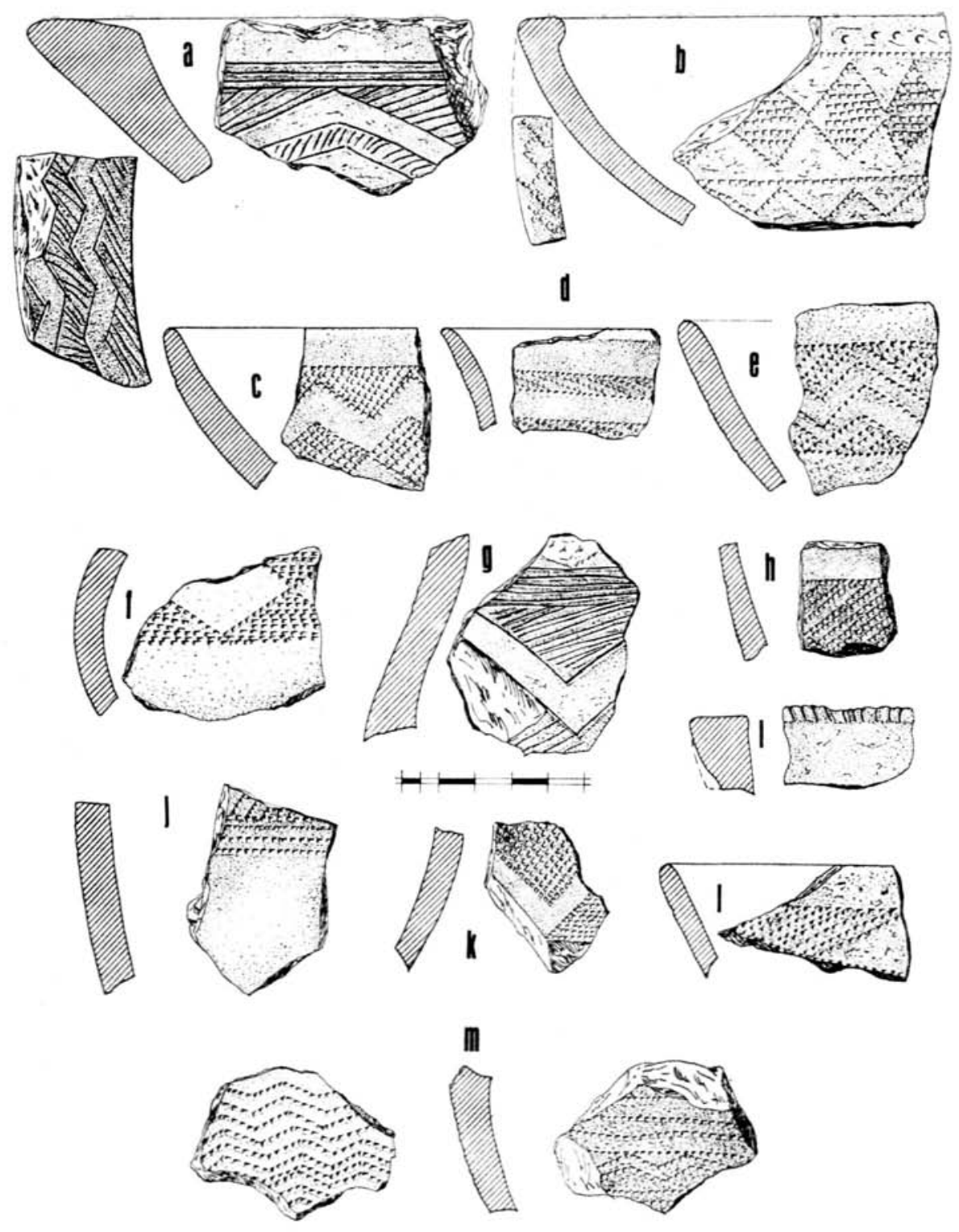

FIG. 9. - Cerro Casar (El Coronil) 